\title{
tropical ecology
}

\section{INSTRUCTIONS FOR AUTHORS}

Potential contributors are advised that careful attention to the details below will greatly assist the Editor and thus speed the processing of their manuscripts. Poorly prepared manuscripts will be returned to authors.

\section{Submission}

All manuscripts must be submitted online via the website:

http://mc.manuscriptcentral.com/jte

Detailed instructions for submitting your manuscript online can be found at the submission website by clicking on the 'Instructions and Forms' link in the top right of the screen; and then clicking on the 'Author Submission Instructions' icon on the following page.

The Editor will acknowledge receipt of the manuscript, provide it with a manuscript reference number and assign it to reviewers. The reference number of the manuscript should be quoted in all correspondence with JTE Office and Publisher

The submission of a manuscript will be taken to imply that the material is original, and that no simila paper has been published or is currently submitted for publication elsewhere. Papers are first inspected for suitability by the Editor or a Board member. Those suitable papers are then critically reviewed by usually two or three expert persons. On their advice the Editor provisionally accepts, or rejects, the paper. If acceptance is indicated the manuscript is usually returned to the author for revision. In some cases a resubmission is invited and on receipt of the new version the paper will be sent to a third referee. If the author does not return the revised or resubmitted version within six months the paper will be classified as rejected. Final acceptance is made when the manuscript has been satisfactorily revised.

Preparation of the manuscript

Authors are strongly advised to consult a recent issue of the JTE to acquaint themselves with the general layout of articles. Manuscripts should be neatly typewritten on A4 paper i.e. $21 \mathrm{~cm} \times 30 \mathrm{~cm}$. Double sided copy is permissible for review purposes, but final submission for publication must be on one side of the paper only. Double spacing must be used throughout, allowing wide margins (about $3 \mathrm{~cm}$ ) on all sides. Main text pages should be numbered.

When a revised $\mathrm{ms}$ is being returned the author is requested to send a copy of the final version on computer disk (Apple Macintosh or IBM compatible PC) together with the hard copy typescript, giving details of the wordprocessing software used (e.g. Microsoft Word, Word or Word Perfect). However, the publisher reserves the right to typeset material by conventional means if an author's disk proves unsatisfactory.

A paper should be prepared using the following format:

Page 1. Title page. This should contain (a) the full title, preferably of less than 20 words and usually containing the geographical location of the study; (b) a running title of not more than 48 letters and spaces; (c) a list of up to 10 key words in alphabetical order suitable for international retrieval systems; (d) the full name of each author; (e) the name of the institution in which the work was carried out; and (f) the present email and postal address of the author to whom proofs should be sent.

Page 2. Abstract. This should be a single paragraph, in passive mode, no more than 200 words long, a concise summary of the paper intelligible on its own in conjunction with the title, without abbreviations or references.

Page 3. et seq. The main body of the text may contain the following sections in the sequence indicated (a) Introduction, (b) Methods, (c) Results, (d)
Discussion, (e) Acknowledgements, (f) Literature Cited, (g) Appendices, (h) Tables, (i) Legends to Figures. An extra section between (a) and (b) for Study Site or Study Species might be necessary.

Main headings should be in capital type and ranged left; sub-headings should be ranged left and italicised. A Short Communication has a title and keywords but no abstract or section headings until Acknowledgements and item Literature Cited.

Acknowledgements should be brief. Notes should be avoided if at all possible; any notes will be printed at the end of the paper and not as footnotes.

Scientific names. The complete Latin name (genus, species and authority) must be given in full for every organism when first mentioned in the text unless a standard reference is available which can be cited. Authorities might alternatively appear in Tables where they are first used.

Units of measurement. Measurements must be in metric units; if not, metric equivalents must also be given. The minus index $\left(\mathrm{m}^{-1}, \mathrm{~mm}^{-3}\right)$ should be used except where the unit is an object, e.g. 'per tree', not 'tree ${ }^{-1}$ '). Use $\mathrm{d}^{-1}, \mathrm{mo}^{-1}$ and $\mathrm{y}^{-1}$ for per day, per month and per year.

Abbreviations. In general, abbreviations should be avoided. Numbers one to nine should be spelled out and number 10 onwards given in figures. Dates should follow the sequence day-month-year, e.g. 1 January 1997*. The 24-hour clock should be used, e.g. $16 \mathrm{~h} 15$

Online supplementary material

Supplementary material is not copy edited or typeset but loaded onto CJO exactly as supplied. Supplementary material must be submitted at the same time as the article and must be clearly marked to distinguish it from the main article text.

Authors should ensure that they mention within thei article that supplementary material is available on CJO.

Language

All papers should be written in English, and spelling should generally follow The Concise Oxford Dictionary of Current English. Abstracts in other languages will be printed if the author so desires together with an abstract in English. All abstracts must be provided by the author.

\section{Literature cited}

References to literature in the text should conform to the 'name-and-date' system: e.g. Fleming (1982); (Goh \& Sasekumar 1980); Montgomery et al. (1981). If a number of references are cited at one place in the text, they should be arranged alphabetically and not chronologically. In the reference list citations should take the forms given below. References with two or more authors should be arranged first alphabetically then chronologically. The names of cited journals should be given in full. Certain foreign language citations may be translated into English, and this should always be done where the English alphabet is not used (e.g. Chinese, Russian, Thai).

FLEMING, T. H. 1982. Foraging strategies of plantvisiting bats. Pp. 287-325 in Kunz, T. H. (ed.). Ecology of bats. Plenum Press, New York. 425 pp.

GOH, A. H. \& SASEKUMAR, A. 1980. The community structure of the fringing coral reef, Cape Rachado. Malayan Nature Journal 34:25-27.

MONTGOMERY, G. G., BEST, R. C. \& YAMAKOSHI, M. 1981. A radio-tracking study of the American manatee Trichechus inunguis (Mammalia: Sirenia). Biotropica 13:81-85.

WHITMORE, T. C. 1984. Tropical rain forests of the Far East. (2nd edition). Oxford University Press, Oxford. $352 \mathrm{pp}$.

Use the following as contractions in text: 'pers. obs.', 'pers. comm.'; but 'unpubl. data', 'in press'. Author should double-check that all references in the text correspond exactly to those in the Literature Cited section.

\section{Tables and figures}

Tables should be typed, together with their titles, on separate pages. Column headings should be brief, with units of measurement in parentheses. Vertical lines should not be used to separate columns. Avoid presenting tables that are too large to be printed across the page; table width must not exceed 80 characters, including spaces between words, figures and columns. Each table should be numbered consecutively with arabic numerals. The author should indicate in the text where tables and figures are to be inserted; all tables and figures must be mentioned in the text.

Authors should ensure that all figures, whether line drawings or photographs, clarify or reduce the length of the text. The.preferred graphics package is Freehand, but many others may be accepted. Please indicate file format and graphics software used for originating artwork files. Typefaces should be restricted to Monotype, Adobe and Bitstream font libraries. High resolution figures should be supplied as TIFF or EPS files, but never as Postscript files, Line drawings should be scanned at $300 \mathrm{dpi}$ and use only conventional Postscript files. Halftones to be scanned at 600 dpi with the preset dot range from 1$96 \%$. If you wish to compress the files use lossless compression package software such as the LZW compression package.

\section{Proofs}

When pdf proofs are received they should be corrected carefully and returned to the publisher without delay, Errors remaining in these first proofs after the author has checked them are the authors responsibility. Any further editorial changes, apart from minor grammatical and syntactical improvements, will be communicated to the author before second proofs are prepared. Ensure that the editorial office knows of changes in your address.

Offprints

Upon publication the corresponding author will automatically receive a pdf of their article from Cambridge University Press. Authors will be offered the opportunity to order paper offprints by using the form supplied at proof stage.

Copyright

Authors of articles published in the journal assign copyright to Cambridge University Press (with certain rights reserved) and you will receive a copyright assignment form for signature on acceptance of your paper. Authors receiving requests for permission to reproduce their work should contact Cambridge University Press for advice.

Business correspondence

Correspondence concerning offprints, copyright, back numbers, advertising and sales to librarie should be addressed to the publishers: Journals Department, Cambridge University Press, The Edinburgh Building, Shaftesbury Road, Cambridge CB2 8RU, UK or Cambridge University Press, 32 Avenue of the Americas, New York, NY 10013-2473 USA. 


\section{JOURNAL OF}

\section{tropical ecology}

\section{CONTENTS}

Seed dispersal of the Brazil nut tree (Bertholletia excelsa) by scatter-hoarding rodents in a central Amazonian forest

J. M. Tuck Haugaasen, T. Haugaasen, C. A. Peres, R. Gribel \& P. Wegge

Mammal and insect predation of chemically and structurally defended Mucuna holtonii (Fabaceae) seeds in a Costa Rican rain forest

\section{E. K. Kuprewicz \& C. García-Robledo}

Estimation of root biomass based on excavation of individual root systems in a primary dipterocarp forest in Pasoh Forest Reserve, Peninsular Malaysia

K. Niiyama, T. Kajimoto, Y. Matsuura, T. Yamashita, N. Matsuo, Y. Yashiro, A. Ripin, Abd. R. Kassim \& N. S. Noor

Parasite infestation and predation in Darwin's small ground finch: contrasting two elevational habitats between islands

\section{J. A. O'Connor, R. Y. Dudaniec \& S. Kleindorfer}

Do fungal pathogens drive density-dependent mortality in established seedlings of two dominant African rain-forest trees?

J. M. Norghauer, D. M. Newbery, L. Tedersoo \& G. B. Chuyong

Temporal separation between jaguar and puma in the dry forests of southern Bolivia

A. Romero-Muñoz, L. Maffei, E. Cuéllar \& A. J. Noss

Environmental factors influencing the establishment, height and fecundity of the annual grass Sorghum intrans in an Australian tropical savanna

K. A. Scott, S. A. Setterfield, M. M. Douglas \& A. N. Andersen

Termite diversity and abundance across fire-induced habitat variability in a tropical moist savanna (Lamto, Central Côte d'Ivoire)

K. Dosso, S. Konaté, D. Aidara \& K. E. Linsenmair

Honeydew foraging by birds in tropical montane forests and pastures of Mexico

H. A. Gamper \& S. Koptur

\section{Short Communications}

Azteca instabilis ants and the defence of a coffee shade tree: an ant-plant association without mutual rewards in Chiapas, Mexico

D. J. Gonthier, G. L. Pardee \& S. M. Philpott

Diet composition of the invasive red-whiskered bulbul Pycnonotus jocosus in Mauritius J. F. Linnebjerg, D. M. Hansen, N. Bunbury \& J. M. Olesen

Reproductive biology of Macleania rupestris (Ericaceae), a pollen-limited Neotropical cloud-forest species in Costa Rica

E. J. Fuchs, J. Ross-lbarra \& G. Barrantes

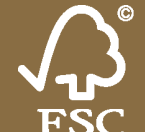

